Brit. F. industr. Med., 1967, 24, 240.

\title{
Miscellanea
}

\section{Protection of Employees with Defective Vision}

\author{
J. P. W. HUGHES and M. A. COOKE \\ From Albright $\mathcal{E}$ Wilson Limited, London
}

An employer has a special duty towards a one-eyed man (Paris v. Stepney Borough Council, I95I) but does not have a special duty to a man with normal sight because employment could normally continue with good monocular vision. Clearly, a man with very defective vision in one eye needs the same consideration as a one-eyed man so we examined the level of visual acuity which should alert the employer to giving a man special consideration.

Two consultant oculists examined a chemist with Leber's syndrome and found 6/24 vision in each eye. One consultant advised taking greater care of the man's eyes because if one eye was lost, or became further damaged, he would have difficulty in continuing laboratory work. His colleague advised that the loss to the man would be of binocular vision and a no greater proportional loss than to the man with normal sight.

Loss of binocular vision is considered greater in a man with poor eyesight because his visual acuity might, as in the present case, go from 6/18 using both eyes to $6 / 24$ using one. We consider that wherever an employee's (corrected) sight is $6 / 18$ or less in either eye then his case should be given special consideration which may then indicate the need for the provision of extra eye protection.

An employer has both morally and legally a special duty towards a one-eyed man. The legal aspect was established in the case of Paris v. Stepney Borough Council (195I) and the report is quoted here:

'If, to the knowledge of his employer, a workman is suffering from a disability which, though it does not increase the risk of an accident occurring while he is at work, does increase the risk of serious injury if an accident should befall him, that special risk of injury is a relevant consideration in determining what precautions the employer should take in fulfilment of his duty to take reasonable care for the safety of each individual workman.

'The appellant was employed as a fitter in the garage of the respondent borough council. To the knowledge of the respondents, he had the use of only one eye. While he was using a hammer to remove a bolt on a vehicle, a chip of metal flew off and entered his good eye, so injuring it that he became totally blind. The respondents did not provide goggles for the appellant to wear, and - there was evidence that it was not the ordinary practice for employers to supply goggles to men employed in garages on the maintenance and repair of vehicles.

'HELD: (i) the condition of the appellant's eyes, the knowledge of the respondents, the likelihood of an accident happening and the gravity of the consequences if an accident should occur, were relevant facts to be taken

Received for publication December 12, 1966. into account in determining the question whether or not the respondents took reasonable precautions for the appellant's safety.

(ii) (Lord Simonds and Lord Morton of Henryton dissenting) in the circumstances the respondents owed a special duty of care to the appellant, and, whether or not goggles should have been supplied to two-eyed workmen engaged in the same work as the appellant, they should have been provided for the appellant, and the respondent's failure to provide them rendered them liable in negligence.'

As an employer has a special duty towards a one-eyed man, clearly he has a special duty to a man who is nearly blind in one eye. At the other end of the scale, a man with normal vision would lose binocular vision and have a restricted field of vision but would be capable of almost any employment, particularly if the eye were lost early in his working life. At what point on the scale, therefore, should special protection be given? It is no point in the argument that the visual acuity might be better in one eye than in the other for it has to be assumed that the better eye would be the one lost or damaged.

The question arose because two consultant oculists, at a considerable interval, examined a chemist. Both diagnosed Leber's syndrome and both found a visual acuity of $6 / 24$ in each eye. 
Leber's disease is a hereditarily acquired retrobulbar optic neuritis with secondary optic atrophy. It is a chronic condition in which improvement or deterioration is unlikely and in which visual acuity cannot be improved by spectacles.

\section{Findings}

The patient was a laboratory chemist aged 39 years. He gave a history of defective vision discovered on routine examination when he was Io years old. His mother, who died while he was still a child, is also said to have had defective vision but there is no other family history of eye disease and the patient otherwise enjoys good health.

On examination the eyes were normal externally. Both discs showed temporal pallor which, with the history and visual acuity, is considered to be significant. The first report disclosed a central scotoma but there was no definite scotoma at the second examination although he still could not recognize colours in the central field of vision.

Visual acuity:

Right-I.0 DS + 0.5 DC ax I80 $=6 / 24$

Left- $6 / 24$ no significant error.

The optic atrophy was considered to be due to Leber's disease, even though the syndrome does not normally occur before puberty. The defect had been stationary for many years and further deterioration was considered to be unlikely.

In all respects but one the consultants' opinions coincided. The first advised extra protection for the man's eyes on the grounds that if he lost an eye he would, as a chemist, be severely restricted in his work. The other advised that the loss to the patient of one eye would be a loss of binocular vision only and that he would suffer proportionately no greater decrease of vision than a normal-sighted person.

\section{Discussion}

Which advice to follow is an intriguing problem for a medical administrator. It is easy 'to play safe' and insist on spectacles at all times and a vizor when working in the laboratory or in the plant. On the other hand, any protective device worn by a man is a restriction on him, and it is morally wrong to condemn a man to a working lifetime of unnecessary restriction. Binocular vision gives twice the area of retina for reception of light, and both eyes together in the case quoted should give an acuity of $6 / 18$; and it could be argued, in a somewhat indifferent analogy, that a person with a bilateral weak grip might hold something, whereas a one-handed man could not. On the other hand, when firing a rifle or 6 threading a needle a normal-sighted individual will convert his binocular vision into monocular by shutting one eye.

Loss of visual capacity has to be considered under several headings. These are acuity, which is largely a function of the macular area alone; visual field, which is largely a function of the peripheral retina; dark adaptation, which is also peripheral; and binocularity, in respect of visual field and depth perception. In monocular blindness acuity is little, if at all, affected. The consultants found that, in this case, the area of binocular field lost was very small-only a small temporal area on the affected side. Dark adaptation was unaffected, but binocular depth perception was lost. (This loss, however, is not always a great handicap, and one monocular Test cricketer, who lost binocular vision during his career, was able to continue playing first-class cricket.) Motivation, and especially the possibility of compensation, plays a major part in individual reaction to injuries. The most important point is that the patient is left with only one eye and is therefore more vulnerable to total blindness.

In this particular case only acuity was affected as the man had a central scotoma with no peripheral loss of field. To a limited extent binocular depth perception would also be reduced. The loss of the vision of one eye would cause about the same proportionate loss as in an individual with normal vision, though it could be argued that a person would be a little worse off in being possibly less able to make use of monocular clues to depth by reason of the lesser acuity in the remaining eye. He would notice the loss of extreme temporal field neither more nor less than a normal-sighted person as his peripheral field was not affected. This is not to say that no one with a visual acuity of $6 / 24$ in each eye and losing the sight of one eye would be left in the same position. It would depend on the diagnosis, and each case has to be considered on its individual merits.

The reasoning regarding the percentage loss of visual capacity illustrates, if anything, the difficulties of attempting to quantify loss of capacity. Such assessments are made, usually with reluctance, mainly for medico-legal purposes. They are only approximately accurate, and individual reactions to visual or any other loss of perceptive faculty are much too variable. 'Vision' is not a single entity but a group of faculties, not all of which may be equally affected in any one case.

Where there is a significant ocular hazard the employer is morally obliged to give protection to all his employees whether or not vision is normal. A one-eyed man may deserve protection at a lower 
level of hazard, but it is principally a matter of the degree of risk.

In deciding to follow the first consultant's advice, our freedom of choice was hampered by the fact that extra protection was already being worn and that the man welcomed it; but it was important to try to decide the correct procedure, both morally and legally, for any future cases.

Campbell-Orr (1954) writes that a patient is certifiable as blind if the vision is less than $3 / 60$ in each eye, and $6 / 9$ in each eye appears to be adequate for practically all purposes. Table I quotes $6 / 126 / 12$ vision as a $10 \%$ defect but the Ministry of Social Security regards this vision as normal and individual opinions might well vary within this limit. In this country, officially, the loss of faculty from the loss of vision of one eye without complications or disfigurement of the eyeball ${ }^{1}$ (the other eye being normal) is $30 \%$. From Table $I$ it can be seen that the assessment of disability increases as the visual capacity of the remaining eye diminishes.

\section{TABLE I}

VISUAL INCAPACITY FOLLOWING INDUSTRIAL INJURY: Prrcentage Defect in Carefully Corrected Errors OF REFRACTION

\begin{tabular}{c|c|c|c|c|c|c|c}
\hline \multirow{2}{*}{$\begin{array}{c}\text { First } \\
\text { Eye }\end{array}$} & \multicolumn{7}{c}{ Second Eye } \\
\cline { 2 - 8 } & $<3 / 60$ & $3 / 60$ & $6 / 60$ & $6 / 24$ & $6 / 18$ & $6 / 12$ & $6 / 9$ \\
\hline$<3 / 60$ & 100 & 90 & 80 & 70 & 60 & 40 & 30 \\
$3 / 60$ & 90 & 80 & 70 & 50 & 45 & 30 & 25 \\
$6 / 60$ & 80 & 70 & 50 & 40 & 35 & 25 & 15 \\
$6 / 24$ & 70 & 50 & 40 & 30 & 25 & 20 & 10 \\
$6 / 18$ & 60 & 45 & 35 & 25 & 20 & 15 & 7 \\
$6 / 12$ & 40 & 30 & 25 & 20 & 15 & 10 & 5 \\
$6 / 9$ & 30 & 25 & 15 & 10 & 7 & 5 & 0 \\
\hline
\end{tabular}

Additions should be made for defects which interfere with the quality of the vision or restrict the visual fields.

[From Campbell-Orr (1954): reproduced by kind permission from the Transactions of the Ophthalmological Society, U.K., 1954, 74, 367.]

The point made in the second opinion was that the decrease of visual capacity would be no greater in the present case of Leber's disease, should one eye be lost, than in a normal-sighted person. But, from Table I, a person with $6 / 24$ in each eye is assessed as having $30 \%$ disability, and blindness in one eye would thus decrease his visual capacity by $40 \%(70 \%$ less $30 \%)$, whereas a normal individual

\footnotetext{
${ }^{1}$ The loss of an eye, with normal vision in the remaining one, is assessed at $40 \%$. We are concerned here with the loss of visual acuity without damage to the eyeball.
}

would have his visual capacity decreased by $30 \%$. Whilst this difference is marginal and may lie within errors of the crude methods of assessment of visual acuity, it is clearly the intention of the compiler of the table to weight the assessment either way when the remaining eye is subnormal; thus from Table II it is seen that a 6/18 vision in each eye would also have a decrease of vision of $40 \%$ $(60 \%$ less $20 \%)$ on losing the use of one eye. The decrease at $6 / 12$ in each eye is $30 \%$ (40\% less $10 \%)$. At the other end of the scale, a near-blind person is assessed at $10 \%$ decrease on the loss of vision in one eye.

TABLE II

Percentage Decrease of Visual Capacity in the Loss of VISION IN ONE EYB

\begin{tabular}{c|c|c|c}
\hline $\begin{array}{c}\text { Vision in } \\
\begin{array}{c}\text { Each of Both } \\
\text { Eyes }\end{array}\end{array}$ & $\begin{array}{c}\% \\
\text { Defect }\end{array}$ & $\begin{array}{c}\% \text { Defect on } \\
\text { Loss of One } \\
\text { Eye }\end{array}$ & $\begin{array}{c}\% \text { Decrease of } \\
\text { Visual } \\
\text { Capacity }\end{array}$ \\
\hline $3 / 60$ & 80 & 90 & 10 \\
$6 / 60$ & 50 & 80 & 30 \\
$6 / 24$ & 30 & 70 & 40 \\
$6 / 18$ & 20 & 60 & 40 \\
$6 / 12$ & 10 & 40 & 30 \\
$6 / 9$ & 0 & 30 & 30 \\
\hline
\end{tabular}

Another point considered was that, although it is essential to test each eye separately, it is the combined visual acuity that is important to the man, so that if he has $6 / 24$ in each eye but can attain $6 / 18$ with both eyes, then the loss of one eye would give an effective decrease of visual acuity of $50 \%$ $(70 \%$ less $20 \%)$. This is in contrast to the man with $6 / 9$ in each eye who can attain $6 / 6$ with both but who still has good (monocular) visual acuity should he lose one eye ( $30 \%$ disability). Again, the man who is nearly blind suffers little extra loss if one eye becomes totally blind.

It is not fortuitous that the Table shows this trend to the centre, for it is those who are just managing to continue with their work who are hardest hit by the loss of one eye. In long-standing cases of visual defect, as in this case from the age of IO, considerable self-selection of occupation occurs, meaning that the person elected his particular choice of career because he, his parents, doctors, and teachers considered that he had enough visual capacity to manage it. The question for the assessor is: 'How much has he lost ?' but for the individual concerned the question is: 'Have I got enough sight left to continue my previous work?' 
The answer to the second question is increasingly likely to be 'yes' towards each end of the scale.

Loss of binocular visual acuity is a greater loss in a man with poor eyesight because visual acuity falls from a higher level using both eyes to a lower level using one, even though the visual acuity in each eye singly was lower. Assuming the worst, in that when visual acuity is lost it will be lost from the better eye, any person with $6 / 18$ or worse visual acuity (i.e., corrected vision) in either eye should be regarded as being in need of special consideration, which may indicate extra protection from further damage to his eyesight where a significant hazard exists. In those employees who do not need spectacles for correction of vision, well-fitting, wide plastic spectacles would be adequate in a chemical works. These should be worn at all times and further protection should be made available should an employee be specially exposed to danger from liquid splashes or irritant vapours or dusts.

We express our sincere gratitude to the two consultants for their valuable comments.

\section{REFERENCES}

Campbell-Orr, H. (1954). Trans. Ophthal. Soc. U.K., 74, 367. Paris v. Stepney Borough Council (I95I). I. All E.R. 42.

\section{Apparent Onset of Coal-Workers' Pneumoconiosis after leaving the Mines N. K. CONI \\ From Cambridge Military Hospital, Aldershot}

The case history is reported of a former coal-miner who, on admission to hospital with acute bronchitis, was found to have a chest radiograph suggestive of pneumoconiosis. However, the film taken on leaving the mines some four years previously was unremarkable, suggesting that the disease had either started or progressed during his four years away from the mines. Among the alternative explanations considered is the possibility that the diagnosis was in error and that the appearance was due to some radiologically similar disease which had chanced to affect an ex-miner. Some of the technical pitfalls inseparable from reliance on radiology are also mentioned as the appearance of progression may have been illusory. Other possibilities are that the disease was not the simple pneumoconiosis of coal-workers but some other form of pneumoconiosis, such as Caplan's syndrome or silicosis, in both of which the natural course of the illness may be quite different. Nevertheless, although it is clear that coal-workers' pneumoconiosis does not normally progress once the subject is removed from the mines, the possibility remains that in a small number of cases it may do so.

One of the recurring problems which confronts clinicians is the patient whose chest radiograph is studded with miliary nodular opacities but who has few symptoms referable to this finding. Quite often examination and investigations prove unrevealing but a history of occupational exposure to a dust known to produce this radiographic appear-

Received for publication September 2, 1966. ance is elicited, and this is welcomed as providing a diagnosis. Unfortunately, sometimes in this situation the patient further reveals that since leaving contact with the dust he has had radiographs which have apparently been normal, and the question then arises whether the radiological changes can in fact be attributed to pneumoconiosis.

The present paper describes such a case in a coal-miner who left the coal-face with a compar- 